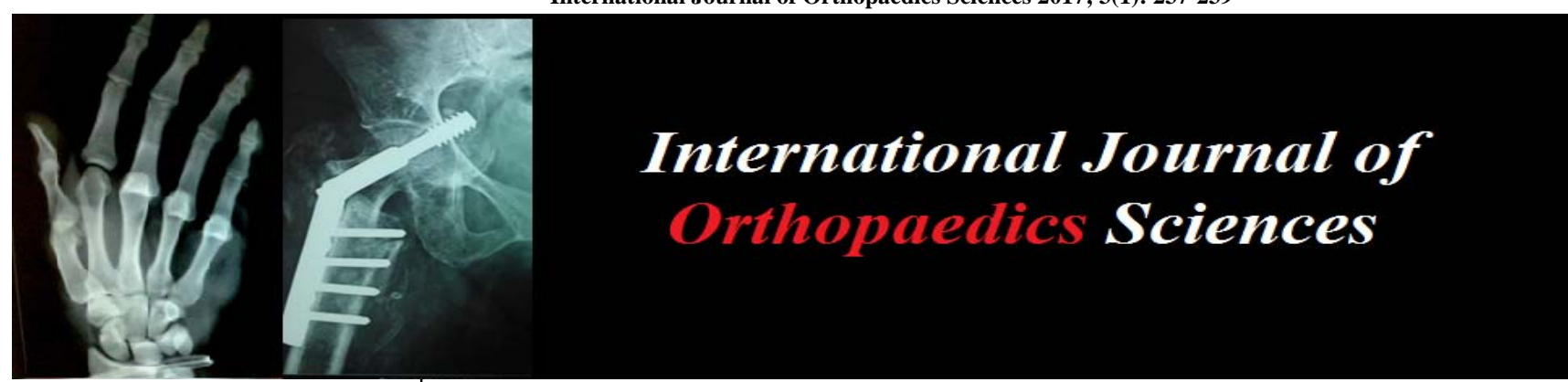

ISSN: 2395-1958

IJOS 2017; 3(1): 237-239

(C) 2017 IJOS

www.orthopaper.com

Received: 09-11-2016

Accepted: 10-12-2016

Dr. Vinoth Karthik

Assistant Professor,

SRM Medical College,

Chennai, Tamil Nadu, India

Dr. Kumareshwaran

Senior Resident,

SRM Medical College,

Chennai, Tamil Nadu, India

Dr. Dilip Kumar

Associate Professor,

SRM Medical College,

Chennai, Tamil Nadu, India

Dr. Sriram Thanigai

Professor, SRM Medical College,

Chennai, Tamil Nadu, India

\section{A study of clinical profile of patients with inter- trochanteric femur fractures}

\author{
Dr. Vinoth Karthik, Dr. Kumareshwaran, Dr. Dilip Kumar and \\ Dr. Sriram Thanigai
}

DOI: http://dx.doi.org/10.22271/ortho.2017.v3.i1d.39

Abstract

Introduction: Trochanteric fractures are one of the commonest injuries sustained predominantly in patients over sixty years of age. They are three to four times more common in women than in men.

Materials and methods: The study was conducted from June 2013 to June 2015 where 25 patients with inter-trochanteric fractures of femur were selected. A prospective study comprising of patients identified for surgical treatment of fracture in the inter-trochanteric region of femur admitted to our hospital.

Aims and Objectives: To Study the clinical profile of patients with inter-trochanteric femur fractures.

Result: The majority of the patients were in the age group of $61-80$ i.e. $60 \%$ followed by in the age group of $81-100$ were $20 \%$; in $21-40$ were $12 \%$ and in $41-60$ were $8 \%$. The majority of the patients were Females i.e. $66.00 \%$ followed by Males $44.00 \%$. The most common mode of injury was Trivial fall was $80 \%$ followed by RTA were $12 \%$ and fall from height $8 \%$. The majority of the patients were of Type 2 Were $56 \%$ followed by Type $4-28 \%$; Type 3 were $12 \%$ and Type 1 were $4 \%$. The majority of the patients were having Right Side of injury i.e. $52 \%$ followed by Left $48 \%$.

Conclusion: From our study it can concluded that the inter-trochanteric femur fractures were more common in old age and in females so this could be attributed by underlying osteoporosis prevalent more in females.

Keywords: Intertrochanteric femur fractures, trivial fall, RTA

\section{Introduction}

Trochanteric fractures are one of the commonest injuries sustained predominantly in patients over sixty years of age. They are three to four times more common in women than in men. These usually occur through bone affected by osteoporosis; trivial fall being the most common mechanism of injury ${ }^{[1]}$.

For many, this fracture is often a terminal event resulting in death due to cardiac, pulmonary or renal complications. Approximately 10 to $30 \%$ of patients die within one year of an intertrochanteric fracture ${ }^{[2]}$.

Earlier, little attention was paid to these fractures, as these, which occur through cancellous bone with excellent blood supply, healed regardless of the treatment. However conservative treatment usually resulted in malunion with varus and external rotation resulting in a short limb gait and a high rate of mortality due to complications of recumbency and immobilization. The goal of treatment of an inter-trochanteric fracture must be restoration of the patient to his or her pre-injury status as early as possible. This led to recommendations for internal fixation of these fractures to increase patient comfort, facilitate nursing care, decrease hospitalization and reduce complications of prolonged recumbency ${ }^{[3]}$. Trochanteric fractures almost invariably occur as a result of a trivial fall [1], 4involving both direct and indirect forces. Direct forces act along the axis of the femur or directly over the greater trochanter to result in trochanteric fractures. Indirect forces, including the pull of iliopsoas muscle on the lesser trochanter and the abductors on the greater trochanter have also been incriminated as a cause of the fracture. Other modes of injury may be either road traffic accidents or a fall from height. In the immediate post-traumatic stage of these fractures, the patient presents with pain, inability to bear weight, externally rotated and shortened extremity ${ }^{[29]}$. The goal of reduction and fixation in any fracture is to achieve union of the fracture with restoration of the normal
Correspondence

Dr. Sriram Thanigai

Professor, SRM Medical College,

Chennai, Tamil Nadu, India 
anatomy and to re-establish the normal force vector acting along the bone. In inter-trochanteric fractures, which usually occur in the elderly, stabilization of the fracture and restoring the patient to his or her pre-injury functional activity at the earliest possible time is essential to prevent complications of recumbency ${ }^{[4]}$.

The ball-and-socket configuration of the hip joint is inherently stable and allows an excellent range of motion in all directions. The two major forces acting on the hip joint are abductor muscle tension and body weight, as defined by the jointreaction force. The mechanics of the hip are such that implants designed for the fixation of fractures must withstand extremely high loads and bending moments. Even when the structural integrity of the hip has been restored, the major muscle forces continue to test the stability of the fracture fixation ${ }^{[18]}$.

\subsection{Aims and Objectives}

To Study Clinical profile of patients with inter-trochanteric femur fractures.

\section{Materials and methods}

The study was conducted June 2013 to June 2015 where 25 patients with inter-trochanteric fractures of femur were selected.

A prospective study comprising of patients identified for surgical treatment of fracture in the inter-trochanteric region of femur admitted to our hospital.

All patients in the study after undergoing routine clinical examination would be subjected to following battery of investigations complete haemogram with ESR Chest X ray PA view Electrocardiogram, AP X ray of pelvis with both hip joints and proximal half femur. Lateral view of the hip was done in patients if pain permits. The patients were then put on skin traction over a Bucks frame. Inter trochanteric Fractures and Intra Capsular Fracture Neck of Femur, Inter trochanteric Fractures with shaft of femur fracture, Non-union, Mal union were excluded from the study. The mode of injury resulting in inter-trochanteric fracture was classified under 3 different categories taking into consideration whether the injury was due to a road traffic accident, trivial fall or a fall from height.

\subsection{Boyd and griffin classification of inter-trochanteric fractures}

Type 1: Fractures that extend along the inter-trochanteric line from the greater to the lesser trochanter.

Type 2: Comminuted fractures, the main fracture being along the inter-trochanteric line but with multiple fractures in the cortex.

Type 3: Fractures that are basically subtrochanteric with at least one fractures passing across the proximal end of the shaft just distal to or at the lesser trochanter. The fracture line runs from supero medial to infero lateral (the reverse obliquity fracture).

Type 4: Fractures of the trochanteric region and proximal shaft with fracture in at least two planes.

\section{Results}

Table 1: Distribution of Patients as per Age

\begin{tabular}{|c|c|c|}
\hline Age group & No. & Percentage (\%) \\
\hline $21-40$ & 3 & $12 \%$ \\
\hline $41-60$ & 2 & $8 \%$ \\
\hline $61-80$ & 15 & $60 \%$ \\
\hline $81-100$ & 5 & $20 \%$ \\
\hline Total & 25 & $100 \%$ \\
\hline
\end{tabular}

The majority of the patients were in the age group of61-80 i.e. $60 \%$ followed by in the age group of $81-100$ were $20 \%$; in $21-$ 40 were $12 \%$ and in $41-60$ were $8 \%$

Table 2: Distribution of the Patients as per Sex

\begin{tabular}{|c|c|c|}
\hline Sex & No. & Percentage (\%) \\
\hline Male & 11 & $44.00 \%$ \\
\hline Female & 14 & $66.00 \%$ \\
\hline Total & 25 & $100.00 \%$ \\
\hline
\end{tabular}

The majority of the patients were Females i.e.66.00\% followed by Males $44.00 \%$

Table 3: Distribution of the patients as per Mode of injury

\begin{tabular}{|c|c|c|}
\hline Mode of injury & No. & Percentage \\
\hline Fall from height & 2 & $8 \%$ \\
\hline RTA & 3 & $12 \%$ \\
\hline Trivial fall & 20 & $80 \%$ \\
\hline Total & 25 & $100 \%$ \\
\hline
\end{tabular}

The most common mode of injury was Trivial fall was $80 \%$ followed by RTA were $12 \%$ and fall from height $8 \%$.

Table 4: Distribution of the Patients as per the Type of fracture

\begin{tabular}{|c|c|c|}
\hline Type of fracture & No. & Percentage (\%) \\
\hline Type 1 & 1 & $4 \%$ \\
\hline Type 2 & 14 & $56 \%$ \\
\hline Type 3 & 3 & $12 \%$ \\
\hline Type 4 & 7 & $28 \%$ \\
\hline Total & 25 & $100 \%$ \\
\hline
\end{tabular}

The majority of the patients were of Type 2 Were $56 \%$ followed by Type $4-28 \%$; Type 3 were $12 \%$ and Type 1 were $4 \%$.

Table 5: Distribution of the Patients as per Side of injury

\begin{tabular}{|c|c|c|}
\hline Side of injury & No. & Percentage (\%) \\
\hline Left & 12 & $48 \%$ \\
\hline Right & 13 & $52 \%$ \\
\hline Total & 25 & $100 \%$ \\
\hline
\end{tabular}

The majority of the patients were having Right Side of injury i.e. $52 \%$ followed by Left $48 \%$.

\section{Discussion}

In elderly people, hip fractures (HFs) are the commonest cause for acute orthopedic admissions ${ }^{[5]}$ and the second leading cause of hospitalization and prolonged length of stay (LOS) ${ }^{[6,}$ 7]. One of the important challenges in the management of HF is to identify patients who are at high risk of poor outcome.

Although HFs dominantly are regarded as homogenous, anatomical types--cervical and trochanteric--differ in bone composition and parameters of proximal femur geometry ${ }^{[8-11]}$ as well as in epidemiological, demographic and clinical characteristics ${ }^{[11-13]}$. It is possible that shared biological mechanisms underlie the site, accompanying co morbidities and risks of postoperative complications and outcomes for each type of HF. Apparently osteoporotic HFs and their outcomes are attributable to complex interactions between multiple factors, however, there may exist some common mechanisms determining specific conditions linked to the HF type. These may be indicators that would enable clinicians to identify patients at risk and provide appropriate management. Various factors have been reported to affect HF outcomes, but 
the role of anatomic location and the potential implications for clinical practice have been addressed in only few investigations with conflicting results. Studies comparing cervical and trochanteric HFs often evaluated only some clinical and/or laboratory parameters or selected outcomes. The prevailing view was that patients with trochanteric compared to cervical HF have poorer outcomes ${ }^{[11]}$. However scientific reports on the association of HF type with preexisting medical conditions, post-operative complications ${ }^{[14]}$, LOS, functional outcomes ${ }^{[15]}$.

In our study we have found that The majority of the patients were in the age group of $61-80$ i.e. $60 \%$ followed by in the age group of $81-100$ were $20 \%$; in $21-40$ were $12 \%$ and in $41-60$ were $8 \%$ respectively this was similar. The majority of the patients were Females i.e. $66.00 \%$ followed by Males $44.00 \%$ this could be the fact that in old age groups females are more prone for the osteoporosis as compared to males these findings are similar to Bostrom et al ${ }^{[16]}$; Kesemenli $\mathrm{C}$ et al ${ }^{[17]}$ in 2001 studied 27 patients with average age of 78 years. Amongst them $14(51 \%)$ patients were females and $13(49 \%)$ patients were males. Kayali $\mathrm{C}$ et al 8 in 2006 studied 42 patients with mean age of 73 years. Amongst them 30 (71.4\%) patients were females and $12(28.57 \%)$ patients were males.

The most common mode of injury was Trivial fall was $80 \%$ followed by RTA were $12 \%$ and fall from height $8 \%$; the majority of the patients were having Right Side of injury i.e. $52 \%$ followed by Left $48 \%$ this was similar to Kesemenli C et $a l^{[17]}$.

\section{Conclusion}

The majority of the patients were in the age group of 61-80; the majority of the patients were Females The most common mode of injury was Trivial fall, followed by RTA So from our study it can concluded that the inter-trochanteric femur fractures were more common in old age and in females so this could be attributed by underlying osteoporosis prevalent more in females.

\section{References}

1. Kaufer H. Mechanics of the Treatment of Hip Injuries. Clin Orthop. 1980; 146:53-61.

2. Kyle RF, Gustilo RB, Premer RF. Analysis of six hundred and twenty-two inter-trochanteric hip fractures. A retrospective and prospective study. J Bone Joint Surg. 1979; 61A:216-21.

3. Kaufer H, Mathews LS, Sonstegard D. Stable Fixation of Intertrochanteric Fractures. J Bone Joint Surg. 1974; 56A:899-907.

4. Lorich DG, Geller DS. Nielson JH. Osteoporotic pertrochanteric hip fractures. Management and current controversies. J Bone Joint Surg. 2004; 86A:398-410.

5. Parker M, Johansen A. Hip fracture. BMJ. 2006; 333:2730. doi: 10.1136/bmj.333.7557.27.[PMC free article] [PubMed] [Cross Ref]

6. Nigwekar SU, Rajda J, Navaneethan SD. Hospitalist care and length of stay in patients with hip fracture: a systematic review. Arch Intern Med. 2008; 168:10101011. doi: 10.1001/archinte.168.9.1010. [PubMed] [Cross Ref]

7. West J, Hippisley-Cox J, Coupland CA, Price GM, Groom LM, Kendrick D et al. Do rates of hospital admission for falls and hip fracture in elderly people vary by socioeconomic status? Public Health. 2004; 118:576-581. doi: 10.1016/j.puhe.2004.02.006. [PubMed] [Cross Ref]

8. Bell KL, Loveridge N, Power J, Garrahan N, Stanton M,
Lunt $\mathrm{M}$ et al. Structure of the femoral neck in hip fracture: cortical bone loss in the inferoanterior to superoposterior axis. J Bone Miner Res. 1999; 14:111-119. doi: 10.1359/jbmr.1999.14.1.111. [PubMed] [Cross Ref]

9. Djuric M, Djonic D, Milovanovic P, Nikolic S, Marshall $\mathrm{R}$, Marinkovic $\mathrm{J}$ et al. Region-specific sex-dependent pattern of age-related changes of proximal femoral cancellous bone and its implications on differential bone fragility. Calcif Tissue Int. 2010; 86:192-201. doi: 10.1007/s00223-009-9325-8.[PubMed] [Cross Ref]

10. Duboeuf F, Hans D, Schott AM, Kotzki PO, Favier F, Marcelli $\mathrm{C}$ et al. Different morphometric and densitometric parameters predict cervical and trochanteric hip fracture: the EPIDOS Study. J Bone Miner Res. 1997; 12:1895-1902.

doi: 10.1359/jbmr.1997.12.11.1895. [PubMed][Cross Ref]

11. Mautalen CA, Vega EM, Einhorn TA. Are the etiologies of cervical and trochanteric hip fractures different? Bone. 1996; 18:133S-137S. doi: 10.1016/87563282(95)00490-4. [PubMed] [Cross Ref]

12. Cauley JA, Lui LY, Genant HK, Salamone L, Browner W, Fink HA et al. Risk factors for severity and type of the hip fracture. J Bone Miner Res. 2009; 24:943-955. doi: 10.1359/jbmr.081246. [PMC article] [PubMed] [Cross Ref]

13. Tanner DA, Kloseck M, Crilly RG, Chesworth B, Gilliland J. Hip fracture types in men and women change differently with age. BMC Geriatr. 2010; 10:12. doi: 10.1186/1471-2318-10-12.[PMC free article] [PubMed] [Cross Ref]

14. Jiang HX, Majumdar SR, Dick DA, Moreau M, Raso J, Otto DD et al. Development and initial validation of a risk score for predicting in-hospital and 1-year mortality in patients with hip fractures. J Bone Miner Res. 2005; 20:494-500. [PubMed]

15. Cornwall R, Gilbert MS, Koval KJ, Strauss E, Siu AL. Functional outcomes and mortality vary among different types of hip fractures: a function of patient characteristics. Clin Orthop Relat Res. 2004; 425:6471. [PMC free article] [PubMed]

16. Bostrom MPG, Simie PM, Lyden JP, Cornell CM, Thorngren KG, Tolo ET. Epidemiology of hip fractures. Bone 1996; 18:57S-63S.

17. Kesemenli C, Subasi M, Arsian H. Treatment of Intertrochanteric fracture in elderly patients with leinbach type endoprosthesis. Ulus Trauma Derg 2001; 7(4):254257

18. Kyle RF, Cabanela ME, Russell TA, Swiontkowski MF, Winquist RA, Zuckerman JD. Instructional Course Lecture, The American Academy of Orthopaedic Surgeons. Fractures of the Proximal Part of the Femur. J Bone Joint Surg. 1994; 76A:924-50. 